Yılmaz Kor* and Deniz Kor

\title{
Current status of the congenital hypothyroidism neonatal screening program in Adana Province, Turkey
}

https://doi.org/10.1515/jpem-2017-0433

Received October 22, 2017; accepted April 18, 2018; previously published online May 11, 2018

\begin{abstract}
Background: Congenital hypothyroidism $(\mathrm{CH})$ is a common cause of mental retardation; it has a worldwide incidence ranging from 1:3000 to 1:4500 live births. Predictably, an increase in the reported incidence of primary $\mathrm{CH}$ occurs when the cut-off levels of thyroid-stimulating hormone are lowered. We aimed to evaluate the results of a congenital hypothyroidism screening program and current status in this study.
\end{abstract}

Methods: Analysis results of 1300 infants who were referred to the endocrinology polyclinic because of suspected $\mathrm{CH}$ within the scope of the Ministry of Health National Neonatal Screening Program were retrospectively evaluated.

Results: The diagnosis of $\mathrm{CH}$ and initiation of treatment were both done in $223(18.5 \%)$ and $10(0.8 \%)$ infants as a result of the initial evaluation and follow-up, respectively. The mean capillary and venous thyroid-stimulating hormone (TSH) levels of 223 patients were 40.78 (5.5100) $\mu \mathrm{IU} / \mathrm{mL}$ and $67.26(10.7-100) \mu \mathrm{IU} / \mathrm{mL}$, respectively. These patients' mean heel prick time was 8.65 (0-30, median: 7) days. The mean age of the 223 infants whose treatment was initiated as a result of the initial evaluation was 19.87 (4-51, median: 20) days, and the mean age of the infants whose treatment was started at follow-up was 43.71 (29-65) days. The duration between heel prick time and venous TSH time was 11.10 (2-28, median: 11) days and was longer than planned (3-5 days).

Conclusions: Although the duration for the diagnosis and initiation of $\mathrm{CH}$ treatment were markedly reduced with the

\footnotetext{
${ }^{*}$ Corresponding author: Yılmaz Kor, Pediatric Endocrinology Division, Republic of Turkey, Ministry of Health, Adana City Hospital, Adana, Turkey, Phone: +90 3223444475, E-mail: dykor05@yahoo.com; and Pediatric Metabolism Division, Republic of Turkey, Ministry of Health, Adana City Hospital, Adana, Turkey

Deniz Kor: Department of Pediatrics, Division of Metabolism, Cukurova University Medical Faculty, Adana, Turkey; and Pediatric Metabolism Division, Republic of Turkey, Ministry of Health, Adana City Hospital, Adana, Turkey
}

implementation of the screening program in Turkey compared to those before the implementation of the screening program, we have not yet achieved the ideal time ( $\leq 14$ days).

Keywords: congenital hypothyroidism; diagnosis time; initiation of treatment; screening program.

\section{Introduction}

Congenital hypothyroidism $(\mathrm{CH})$ is a common cause of mental retardation; it has a worldwide incidence ranging from 1:3000 to 1:4500 live births [1]. Predictably, an increase in the reported incidence of primary $\mathrm{CH}$ occurs when the cut-off levels of thyroid-stimulating hormone (TSH) are lowered [2]. CH causes neuronal migration disorder due to thyroid hormone deficiency, and serious $\mathrm{CH}$ delays psychomotor development. Neonatal mass screening is performed worldwide and is useful for detecting $\mathrm{CH}$. In many countries, neonatal screening (NS) programs are performed for the early diagnosis and treatment of hypothyroidism. Most infants with $\mathrm{CH}$ are normal at birth and show no signs, emphasizing the importance of screening programs in the early detection of $\mathrm{CH}$. Although the problem of $\mathrm{CH}$ has been resolved in developed countries by the implementation of NS programs since 1972, the same cannot be said for developing countries that still have no NS programs for $\mathrm{CH}$ [3-7]. The $\mathrm{CH}$ screening program in Turkey has been implemented since 2006 [8]. The European Society for Pediatric Endocrinology held a meeting to reach a clinical and therapeutic consensus on $\mathrm{CH}$ to revise previous guidelines in 2010 and published new guidelines in 2014 [9]. Although CH screening programs were implemented years ago, the optimal screening methods and cut-off levels of TSH remain controversial. We aimed to evaluate the results of congenital hypothyroidism screening program and current status in this study.

\section{Materials and methods}

In the NS program, if the first TSH level is $>20 \mu \mathrm{IU} / \mathrm{mL}$, the infant is directed to an endocrinology polyclinic for measuring venous TSH and free thyroxine (fT4) levels. If TSH levels are between 5.5 and 
$20 \mu \mathrm{IU} / \mathrm{mL}$, a control heel prick is performed again; if the level is again over $5.5 \mu \mathrm{IU} / \mathrm{mL}$, venous TSH and fT4 levels should be measured (Figure 1). Heel prick is repeated if it is not properly performed.

Analysis results of 1300 infants who were referred to a polyclinic between May 2012 and June 2016 because of suspected CH within the scope of the Ministry of Health National Neonatal Screening Program were retrospectively evaluated. Of these, 95 were excluded due to reasons such as an incomplete screening program data collection form, initiation of treatment in another health facility or trisomy. For the remaining 1205 infants, data in the screening form (date of heel prick time, capillary TSH level, date of admission to the hospital, time between heel prick time and admission to the hospital) and venous TSH, fT4 and thyroid ultrasonography (USG) results were evaluated. Criteria for the initiation of treatment are as follows: if fT4 levels are low regardless of TSH levels; if age is $\leq 7$ days and TSH levels are $>30 \mu \mathrm{IU} / \mathrm{mL}$; if age is between 8 and 28 days and TSH levels are $>20$ $\mu \mathrm{IU} / \mathrm{mL}$; and if age is $>28$ days and TSH levels are $>10 \mu \mathrm{IU} / \mathrm{mL}$, regardless of normal fT4 levels (Figure 1). TSH levels of $<5 \mu \mathrm{IU} / \mathrm{mL}$ were considered as normal. If TSH levels were above $5 \mu \mathrm{IU} / \mathrm{mL}$, thyroid USG and follow-up were planned. Thyroid volume was calculated using the following formula: $[(\mathrm{A} \times \mathrm{B} \times \mathrm{C}) / 1000+(\mathrm{A} \times \mathrm{B} \times \mathrm{C}) / 1000] \times 0.523$ [5]. If thyroid volume was $<0.7 \mathrm{~mm}^{3}$, hypoplasia was considered. Elecsys reagent kits were used to measure the TSH, and fT4 levels. They were analyzed using Electrochemiluminescence Immunoassay "ECLIA" method and Roche Elecsys E170 device (Roche Diagnostics GmbH,
Sandhofer Strasse, Mannheim, Germany). TSH levels between 0.73 and $8.35 \mu \mathrm{IU} / \mathrm{mL}$ and fT4 levels between 0.92 and $1.99 \mathrm{ng} / \mathrm{dL}$ were given as "normal".

This study was approved by the Ethics Committee of the Cukurova University Faculty of Medicine.

\section{Statistical analysis}

Data were analyzed with the Statistical Package for the Social Sciences 18 program. Frequency distribution was used to describe the sample and mean \pm standard deviation (SD) was used to describe continuous data. Descriptive statistics (mean and SD), and the t-test were used.

\section{Results}

In total, 2191 heel prick blood samples taken from 1205 infants born in Adana city between May 2012 and June 2016 (1.82 samples/baby) were evaluated. In total, 575 infants (47.7\%) were females and 630 (52.3\%) were males.

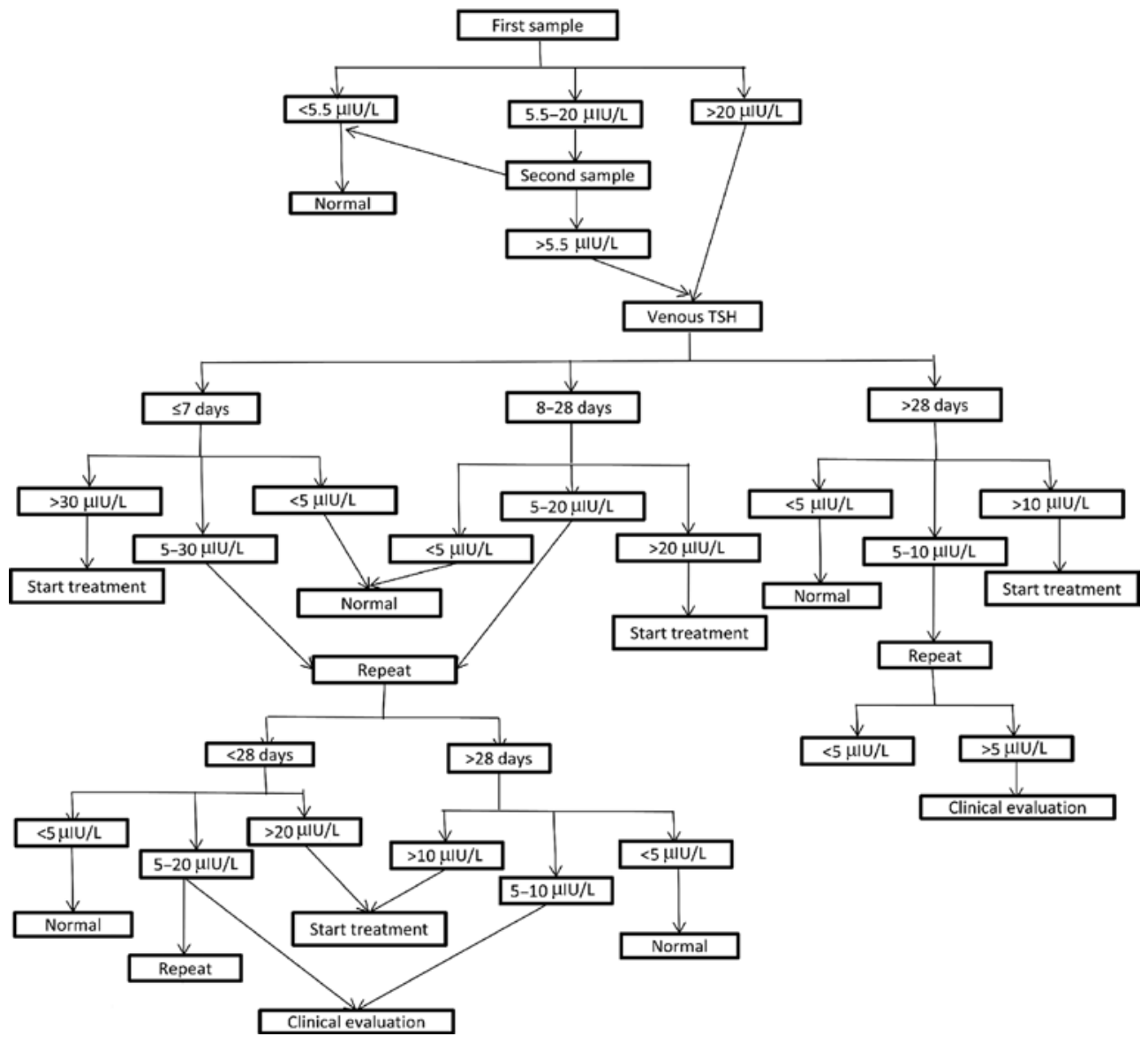

Figure 1: Flow chart for screening test and evaluation of venous TSH results. 
The venous TSH test was performed; one capillary blood sample was obtained from 254 infants (21.1\%), two capillary blood samples from 570 infants (47.3\%), and three capillary blood samples from 381 infants (31.6\%). The mean when the first heel prick time was performed was 10.15 (0115) days; the mean age of the infants on admission to the hospital was 24.54 (4-168) days, and the mean \pm SD duration between the first heel prick time and admission to the hospital was 14.38 (2-164) days in all cases (Table 1).

The mean capillary and venous TSH levels were 29.79 (5.07-100) $\mu \mathrm{IU} / \mathrm{mL}$ and $15.89(0.74-100) \mu \mathrm{IU} / \mathrm{L}$, respectively in all cases. The capillary TSH, venous TSH levels and time taken for samples in all cases are shown in Table 1. The diagnosis of $\mathrm{CH}$ and initiation of treatment were both done in $223(18.5 \%)$ and $10(0.8 \%)$ infants as a result of the initial evaluation and follow-up, respectively. The venous TSH levels of 175 (14.5\%) infants at follow-up were regarded as normal. In the initial assessment, the mean venous TSH levels of 10 infants whose treatment was initiated at follow-up was 9.99 (6.53-19.07) $\mu \mathrm{IU} / \mathrm{mL}$, while the mean TSH levels at the initiation of treatment was 15.01 (10.2-22) $\mu \mathrm{IU} / \mathrm{mL}$. In a 17-day-old infant with hypothyroidism, although the TSH level in the first capillary sample was $6.96 \mu \mathrm{IU} / \mathrm{mL}$ and that in the second capillary sample was $5.99 \mu \mathrm{IU} / \mathrm{mL}$, the venous TSH level was $100 \mu \mathrm{IU} / \mathrm{mL}$ and the fT4 level was $0.3 \mathrm{ng} / \mathrm{dL}$ when the treatment was initiated.

Of the 223 infants whose treatment was initiated according to the first evaluation results, there were 103 (46.2\%) females and 120 (53.8\%) males. The mean heel prick time, venous TSH time, and duration between heel prick time and venous TSH time of these patients were 8.65 (0-30), 19.87 (4-51) and 11.22 (2-31) days, respectively. The mean capillary TSH level was $40.78(5.5-100) \mu \mathrm{IU} / \mathrm{mL}$, and the mean venous TSH levels of these 223 patients was
$67.26(10.7-100) \mu \mathrm{IU} / \mathrm{mL}$. The mean fT4 levels in the 223 patients diagnosed with $\mathrm{CH}$ was $0.61(0-1.4) \mathrm{ng} / \mathrm{dL}$. When the fT4 levels in these patients was evaluated according to the reference range given by the laboratory, 74 infants (33.2\%) were diagnosed as having severe hypothyroidism (fT4<0.4 ng/dL).

The mean age of the 223 infants whose treatment was initiated as a result of the initial evaluation was 19.87 (451) days, and the mean age of the infants whose treatment was started at follow-up was 43.71 (29-65) days. It was determined that treatment was initiated in six patients (2.7\%) early than 7 days, in 51 patients $(22.9 \%)$ between 8 and 14 days, in 137 patients (61.4\%) between 15 and 28 days, in 29 patients (13\%) later than 28 days. In other words, the treatment was started in $206(88.4 \%)$ patients in the first month, in $25(10.7 \%)$ patients between 1 and 2 months, and in two (0.9\%) patients after 2 months. The distribution of infants according to their age at the initiation of treatment was shown in Table 2.

When the capillary TSH cut-off levels were changed for research purposes, $\mathrm{CH}$ was diagnosed in only $82(31.2 \%)$ of 263 infants with capillary TSH levels of $\geq 40 \mu \mathrm{IU} / \mathrm{mL}$ and in 11 (50\%) of 22 infants with capillary TSH levels of $\geq 100 \mu \mathrm{IU} /$ $\mathrm{mL}$ (Table 3). This suggests that the false positive rate of the screening program is high. While the disease was not diagnosed in any of the 37 infants at follow-up, initial venous TSH levels ranged between 5 and $6 \mu \mathrm{IU} / \mathrm{mL}$. Treatment was initiated in $10(7.2 \%)$ of 138 infants at follow-up; their initial venous TSH levels ranged between 6 and $20 \mu \mathrm{IU} / \mathrm{mL}$. The initial TSH levels of seven of these 10 patients in whom treatment was initiated were between 6.53 and $9.1 \mu \mathrm{IU} / \mathrm{mL}$.

Thyroid USG was performed for all infants diagnosed with $\mathrm{CH}$. Totally, 165 (71\%) infants were found to be normal, 57 (24.5\%) were found to have hypoplasia, 10 (4.1\%) were found to have agenesis and one $(0.4 \%)$ was

Table 1: The capillary TSH, venous TSH levels and sample taken times in all cases.

\begin{tabular}{llllll}
\hline & CH $(-)$ & CH $(+)$ & Follow-up & Diagnosed at follow-up & Total \\
\hline $\mathrm{n}(\%)$ & $797(66.2 \%)$ & $223(18.5 \%)$ & $175(14.5 \%)$ & $10(0.8 \%)$ & $1205(100 \%)$ \\
Capiller TSH, & $26.68 \pm 19.06$ & $40.78 \pm 26.46$ & $29.99 \pm 21.23$ & $27.67 \pm 19.26$ & $29.79 \pm 21.60$ \\
mean \pm SD (min-max) & $(5.25-100)$ & $(5.5-100)$ & $(5.07-100)$ & $(8.36-79)$ & $(5.07-100)$ \\
Venous TSH, $\mu \mathrm{IU} / \mathrm{mL}$, & $3.26 \pm 1.09$ & $67.26 \pm 34.38$ & $8.26 \pm 2.56$ & $15.01 \pm 4.21$ & $15.89 \pm 28.69$ \\
mean \pm SD (min-max) & $(0.74-4.99)$ & $(10.7-100)$ & $(5.1-16.76)$ & $(10.2-22)$ & $(0.74-100)$ \\
Heel prick time, day & $10.59 \pm 10.51$ & $8.65 \pm 6.31$ & $10.27 \pm 7.06$ & $6.40 \pm 7.95$ & $10.15 \pm 9.42$ \\
& $(0-115$, median: 8) & $(0-30$, median: 7) & $(0-30$, median: 9) & $(0-23$, median: 2.5) & $(0-115$, median: 8) \\
Venous TSH time, day & $26.40 \pm 15.12$ & $19.87 \pm 7.63$ & $22.31 \pm 8.83$ & $43.71 \pm 14.02$ & $24.54 \pm 13.46$ \\
& $(7-168$, median: 24) & $(4-51$, median: 20) & $(7-59$, median: 21) & $(29-65$, median: 39.5) & $(4-168$, median: 22) \\
Duration between heel & $15.81 \pm 11.05$ & $11.22 \pm 4.57$ & $12.04 \pm 5.53$ & $12.10 \pm 6.21$ & $14.38 \pm 9.66$ \\
prick time and venous & $(2-164$, median: 13) & $(2-31$, median: 11) & $(3-37$, median: 11) & $(6-28$, median: 11) & $(2164$, median: 12) \\
TSH time, day & & & & & \\
\hline
\end{tabular}


Table 2: The distribution of infants according to their age at the initiation of treatment.

\begin{tabular}{|c|c|c|c|c|}
\hline & & $\mathbf{n}$ & $\begin{array}{r}\mathrm{TSH}, \mu \mathrm{IU} / \mathrm{mL}, \\
\text { mean } \pm \mathrm{SD}\end{array}$ & $\begin{array}{r}\text { Free } \mathrm{T4}, \mathrm{ng} / \mathrm{dL}, \\
\text { mean } \pm \mathrm{SD}\end{array}$ \\
\hline \multirow[t]{4}{*}{$\leq 7$ day } & $\mathrm{CH}(-)$ & 3 & $3.41 \pm 0.33(3.20-3.80)$ & $1.68 \pm 0.40(1.40-2.14)$ \\
\hline & $\mathrm{CH}(+)$ & 6 & $50.88 \pm 16.25(33.02-70.60$ & $0.93 \pm 0.35(0.30-1.30)$ \\
\hline & Follow-up & 1 & 7.80 & 1.20 \\
\hline & Total & 10 & $32.33 \pm 26.86(3.20-70.60)$ & $1.18 \pm 0.48(0.30-2.14)$ \\
\hline \multirow[t]{5}{*}{ 8-14 day } & $\mathrm{CH}(-)$ & 84 & $3.54 \pm 1.05(0.74-4.99)$ & $1.52 \pm 0.27(0.80-2.17)$ \\
\hline & $\mathrm{CH}(+)$ & 51 & $76.27 \pm 29.16(20.63-100)$ & $0.62 \pm 0.33(0.00-1.40)$ \\
\hline & Follow-up & 31 & $9.13 \pm 2.33(5.34-13.70)$ & $1.41 \pm 0.24(0.90-1.80)$ \\
\hline & $\mathrm{CH}(+)$ at follow-up ${ }^{\mathrm{a}}$ & 4 & $11.14 \pm 5.49(7.11-19.07)$ & $1.48 \pm 0.35(1.17-1.92)$ \\
\hline & Total & 170 & $26.56 \pm 36.39(0.74-100.00)$ & $1.23 \pm 0.49(0.00-2.17)$ \\
\hline \multirow[t]{5}{*}{ 15-28 day } & $\mathrm{CH}(-)$ & 471 & $3.31 \pm 1.05(0.81-5.24)$ & $1.38 \pm 0.23(0.90-2.14)$ \\
\hline & $\mathrm{CH}(+)$ & 137 & $68.99 \pm 35.40(14.73-100)$ & $0.57 \pm 0.30(0.02-1.33)$ \\
\hline & Follow-up & 104 & $8.51 \pm 2.75(5.10-16.76)$ & $1.24 \pm 0.27(0.70-1.84)$ \\
\hline & $\mathrm{CH}(+)$ at follow-up ${ }^{\mathrm{a}}$ & 4 & $9.64 \pm 4.34(6.53-16.01)$ & $1.33 \pm 0.22(1.12-1.61)$ \\
\hline & Total & 716 & $16.67 \pm 29.87(0.81-100.00)$ & $1.21 \pm 0.40(0.02-2.14)$ \\
\hline \multirow[t]{5}{*}{$>28$ day } & $\mathrm{CH}(-)$ & 239 & $3.05 \pm 1.13(0.74-4.98)$ & $1.38 \pm 0.20(0.90-2.15)$ \\
\hline & $\mathrm{CH}(+)$ & 29 & $48.27 \pm 36.42(10.71-100)$ & $0.67 \pm 0.27(0.10-1.20)$ \\
\hline & Follow-up & 38 & $6.86 \pm 1.52(5.28-11.43)$ & $1.34 \pm 0.23(0.80-2.10)$ \\
\hline & $\mathrm{CH}(+)$ at follow-up ${ }^{\mathrm{a}}$ & 2 & $8.36 \pm 0.02(8.35-8.38)$ & $1.27 \pm 0.14(1.17-1.37)$ \\
\hline & Total & 308 & $7.81 \pm 17.16(0.74-100)$ & $1.30 \pm 0.30(0.10-2.15)$ \\
\hline
\end{tabular}

aThe initial venous TSH values.

Table 3: Rate of the disease according to venous TSH results when capillary TSH cut-off levels changed for research purpose.

\begin{tabular}{lrrrr}
\hline If capillary TSH cut-off level & CH (-) & CH (+) & Follow-up & CH (+) at follow-up \\
\hline$\geq 40$ & $137(52.1 \%)$ & $82(31.2 \%)$ & $43(16.3 \%)$ & $1(0.4 \%)$ \\
$\geq 60$ & $60(45.8 \%)$ & $53(40.5 \%)$ & $17(13.0 \%)$ & $1(0.8 \%)$ \\
$\geq 80$ & $21(36.2 \%)$ & $30(51.7 \%)$ & $7(12.1 \%)$ & 0 \\
$\geq 100$ & $8(36.4 \%)$ & $11(50 \%)$ & $3(13.6 \%)$ & 0 \\
\hline
\end{tabular}

found to have goiter. The thyroglobulin level of the infant with goiter was $12,138 \mathrm{ng} / \mathrm{mL}$, and the infant was diagnosing as having dyshormonogenesis.

\section{Discussion}

The $\mathrm{CH}$ screening program has been implemented in Turkey by the Ministry of Health since 2006. It is based on measuring TSH levels by pricking the heel between the third and fifth day of life. In practice, however, if an infant is discharged early, heel blood is taken within the first $48 \mathrm{~h}$ of life. Although every birth is important in terms of registering the baby, this practice primarily increases the false positive and recall rate. Accurate and timely taking of heel blood will reduce the cost of the screening program and result in a diagnosis being made earlier. The most important goals of $\mathrm{CH}$ screening programs are the early diagnosis and treatment of $\mathrm{CH}$. The verification of diagnosis in the first 14 days and initiation of treatment are important for normal neuropsychiatric development [10]. In the review of the literature, among 11 studies comparing initiation of treatment at an earlier age (12-30 days) with that at a later age ( $>30$ days), infants in whom treatment was initiated at the earlier age averaged 15.7 intelligence quotient (IQ) points higher [11]. In our study, the mean time when heel prick time was performed for 223 patients in whom treatment was initiated was $8.65(0-30)$ days, the mean time for diagnosis was 19.87 (4-51) days, and the mean duration between the first heel prick time and admission to the hospital was 11.22 (2-31) days. In studies conducted in various countries, the time for initiating treatment varies from 8.5 to 46 days [12-14]. In a study conducted in our country comparing the results before and after the screening program; the mean age at diagnosis was found to be 292 days before and 35.2 days after the screening program [15]. In a similar study conducted in Turkey after screening 
program; age at the start of treatment was reported as $38.1 \pm 58$ days, and it was emphasized that the period of time between heel blood and venous blood sampling was very long. They also stated that the venous TSH collected at different centers delayed the treatment [8]. Kendirci et al. [16] reported in their study, day of screening as 8.44 and time of the treatment initiation as 19.7 days. These findings are almost the same as in our study, but they only assessed cases diagnosed with congenital hypothyroidism. In another study conducted before the mandatory screening program in our country, age at the initiation of replacement therapy was reported as 23 days and emphasized the high incidence of congenital hypothyroidism [7]. The age at the start of treatment in our study is the earliest since the implementation of the screening program. However, it is still necessary to extend and improve the screening schedule.

Although worldwide screening programs have become widespread, the capillary TSH cut-off level is still controversial. The difference in the cut-off level affects false positive and false negative rates. The recall rate and $\mathrm{CH}$ frequency increased in countries with low cut-off levels [5, 17-19]. In our study, the mean capillary TSH level and the mean venous TSH level were 29.79 (5.07-100) $\mu \mathrm{IU} / \mathrm{mL}$ and $15.89(0.74-100) \mu \mathrm{IU} / \mathrm{mL}$ in all cases, respectively. The number of patients in whom treatment was initiated, treatment according to the initial and control venous TSH levels, was $223(18.5 \%)$ and 10 (0.8\%), respectively. The mean venous TSH levels of the 10 patients in whom treatment was initiated at follow-up was 9.99 (6.5319.07) $\mu \mathrm{IU} / \mathrm{mL}$. When treatment was initiated, it was 15.01 $(10.2-22) \mu \mathrm{IU} / \mathrm{mL}$. The initial TSH levels of the seven infants in whom treatment was initiated were between 6.53 and $9.1 \mu \mathrm{IU} / \mathrm{mL}$. As suggested previously [20], if we considered TSH lower limit of $9.1 \mu \mathrm{IU} / \mathrm{mL}$, these seven patients would not have been diagnosed. If we followed the cases according to the reference range given by our hospital laboratory or as suggested in previous studies, $9.1 \mu \mathrm{IU} / \mathrm{mL}$ for venous TSH, the diagnosis of seven patients could be skipped. A value of 6.53 is the reliable lower value we found in this study. Therefore, we think that the reference range normally given by laboratories for TSH should be evaluated together with clinical and radiological data.

If the capillary TSH level is $>40 \mu \mathrm{IU} / \mathrm{mL}$, it is recommended to initiate treatment without waiting, if venous TSH level cannot be measured on the same day [21]. In our study, when we examined the capillary and venous TSH levels, we found that only $31.2 \%$ of infants with capillary TSH levels of $>40 \mu \mathrm{IU} / \mathrm{mL}$ had $\mathrm{CH}$. Likewise, we found $\mathrm{CH}$ in only $50 \%$ of infants with capillary TSH levels of $>100 \mu \mathrm{IU} / \mathrm{mL}$. For this reason, we believe that if the capillary TSH level is $>40 \mu \mathrm{IU} / \mathrm{mL}$ and if venous TSH level cannot be measured on the same day, treatment is initiated based on clinical findings such as prolonged jaundice, constipation, difficulty in feeding and hypothermia. Otherwise, more than half of the infants will be given unnecessary treatment, which will lead to a psychological negative effect on their parents.

In a study investigating the relationship between the timing of the initiation of $\mathrm{CH}$ treatment and the dose of L-thyroxine given and the level of IQ, the best IQ level was found in patients who received L-thyroxine at a high dose and in whom treatment was initiated before 13 days of life [10]. In our study, only 57 (25\%) infants were diagnosed in the first 14 days of life and 137 (88\%) infants were diagnosed in the first 28 days of life. Although we cannot start at the desired time, the results of the screening program considerably improved compared with earlier times.

To conclude, the NS program is widely used because it is one of the most common tools to prevent mental retardation. Treatment should be initiated as early as possible to prevent the effect of the disease on neuromotor development. In this study, we found that although the duration for the diagnosis and initiation of treatment of $\mathrm{CH}$ were markedly reduced with the implementation of the screening program in Turkey compared to those before the implementation of the screening program, we have not yet achieved the ideal time. Eliminating human-induced negative factors will contribute to the development of healthier generations. For this reason, problems must be identified and overcome to further improve the screening program.

Author contributions: All the authors have accepted responsibility for the entire content of this submitted manuscript and approved submission.

Research funding: None declared.

Employment or leadership: None declared.

Honorarium: None declared.

Competing interests: The funding organization(s) played no role in the study design; in the collection, analysis, and interpretation of data; in the writing of the report; or in the decision to submit the report for publication.

\section{References}

1. Rastogi MV, LaFranci SH. Congenital hypothyroidism. Orphanet J Rare Dis 2010;5:17.

2. Ford G, La Franchi SH. Screening for congenital hypothyroidism: a world wide view of strategies. Best Pract Res Clin Endocrinol Metab 2013;28:175-87. 
3. Deladoëy J, Ruel J, Giguère Y, Van Vliet G. Is the incidence of congenital hypothyroidism really increasing? A 20-year retrospective population-based study in Québec. J Clin Endocrinol Metab 2011;96:2422-9.

4. La Franchi SH. Newborn screening strategies for congenital hypothyroidism: an update. J Inherit Metab Dis 2010;33:225-33.

5. Mengreli C, Kanaka-Gantenbein C, Girginoudis P, Magiakou MA, Christakopoulou I, et al. Screening for congenital hypothyroidism: the significance of threshold limit in false-negative results. J Clin Endocrinol Metab 2010;95:4283-90.

6. Büyükgebiz A. Newborns screening for congenital hypothyroidism. J Clin Res Pediatr Endocrinol 2013;5(Suppl 1):8-12.

7. Yordam N, Ozon A. Neonatal thyroid screening: methods, efficiency, failures. Pediatr Endocrinol Rev 2003:1(Suppl. 2):177-84.

8. Kuşdal Y, Yeşiltepe-Mutlu G, Özsu E, Çizmecioğlu FM, Hatun Ş. Congenital hypothyroidism screening program in Turkey: a local evaluation. Turkish J Pediatr 2012;54:590-5.

9. Léger J, Olivieri A, Donaldson M, Torresani T, Krude H, et al. European Society for Pediatric Endocrinology consensus guidelines on screening, diagnosis, and management of congenital hypothyroidism. Horm Res Paediatr 2014;81:80-103.

10. Bongers-Schockking JJ, de Muinick Keizer-Schrama SM. Influence of timing and dose of thyroid hormone replacement on development in infants with congenital hypothyroidism. J Pediatr 2000;136:292-7.

11. LaFranchi SH, Austin J. How should we be treating children with congenital hypothyroidism? J Pediatr Endocrinol 2007;20:559-78.

12. Golbahar J, Al-Khayyat H, Hassan B, Agab W, Hassan E, et al. Neonatal screening for congenital hypothyroidism: a retrospec- tive hospital based study from Bahrain. J Pediatr Endocrinol Metab 2010;23:39-44.

13. Daher R, Beaini M, Mahfouz R, Cortas N, Younis KA. A neonatal screening in Lebanon: results of five years experience. Ann Saudi Med 2003;23:16-9.

14. Cornejo V, Raimann E, Cabello JF, Valliente A, Becerra C, et al. Past, present and future of newborn screening in Chile. J Inherit Metab Dis 2010;33:301-6.

15. Eren E, Sağlam H, Zengin A, Gül Y, Papatya-Çakır ED, et al. Konjenital Hipotiroidili Olguların Değerlendirilmesi: Ulusal Tarama Programının Etkisi. J Curr Pediatr 2011;9:28-33.

16. Peltek Kendirci HN, Aycan Z, Sağsak E, Keskin M, Çetinkaya S. The evaluation of transient hypothyroidism in patients diagnosed with congenital hypothyroidism. Turk J Med Sci 2015;45:745-50.

17. Korada SM, Pearce M, Ward Platt MP, Avis M, Turner S, et al. Difficulties in selecting an appropriate neonatal TSH screening threshold. Arch Dis Child 2010;95:169-73.

18. Loeber JG. Neonatal screening in Europe: the situation in 2004. J Inherit Metab Dis 2007;30:430-8.

19. Corbetta C, Weber G, Cortinovis F, Calebiro D, Passoni A, et al. A 7-year experience with low blood TSH cut off levels for neonatal screening reveals an unsuspected frequency of congenital hypothyroidism (CH). Clin Endocrinol (Oxf) 2009;71:739-45.

20. Rose SR, Brown RS. Update of newborn screening and therapy for congenital hypothyroidism. Pediatrics 2006;117:2290-303.

21. Nagasaki K, Minamitani K, Anzo M, Adachi M, Ishii T, et al. Guidelines for mass screening of congenital hypothyroidism (2014 revision). Clin Pediatr Endocrinol 2015;24:107-33. 